\title{
Consequences of Combining Strength and Endurance Training Regimens
}

A common belief among many clinicians and trainers is that intensive simultaneous training for muscle strength and cardiovascular endurance is counterproductive. To test this premise, 14 healthy, untrained men trained four days per week for 20 weeks on a bicycle ergometer for endurance (END Group, $n=4$ ), on an isckinetic device for increased torque production (ITP Group, $n=5$ ), or on both devices (COMBO Group, $n=5$ ). The ITP and COMBO groups had equal torque gains througbout the study ( $234 \pm 45$ and $232 \pm 23 \mathrm{~N} \cdot \mathrm{m}$, respectively). After 11 weeks, both END and COMBO groups bad similar gains in maximal oxygen consumption ( $\mathrm{VO}_{2}$ max) (in milliliters per kilogram of body weight per minute). During the last half of the study, bowever, the END Group had a signifcant gain in $\dot{V O}_{2 \text { max }}(\mathrm{p}<.05)$ of $4.7 \pm 1.2 \mathrm{~mL} \cdot \mathrm{kg}^{-1} \cdot \mathrm{min}^{-1}$, whereas the COMBO Group had a nonsignificant gain ( $\mathrm{p}>.05$ ) of $1.8 \pm 0.6 \mathrm{~mL}^{-1} \mathrm{~kg}^{-1} \cdot \mathrm{min}^{-1}$. In harmony with this finding, the END Group showed a significant increase $(\mathrm{p}<.05)$ in citrate synthase activity $\left(15.5 \pm 7.9 \mu \mathrm{mol} \cdot \mathrm{g}^{-1} \cdot \mathrm{min}^{-1}\right)$, whereas the COMBO Group bad no significant increase. The authors concluded that simultaneous training may inbibit the normal adaptation to either training program when performed alone. The extent of the interference probably depends on the nature and intensity of the individual training program. [Nelson AG, Arnall DA, Loy SF, et al: Consequences of combining strength and endurance training regimens. Phys Ther 70:287-294, 1990]

Key Words: Energy expenditure; Exercise, strengthening; Functional training and activities; Oxygen consumption.
The adaptation of skeletal muscle to exercise training is well documented. ${ }^{1-3}$ The nature of the adapta- tion appears to be specific to the training modality. Endurance training induces increases in mitochondrial
A Nelson, PhD, is Assistant Professor in Kinesiology, Louisiana State University, Baton Rouge, LA 70803 .

D Arnall, PhD, PT, FACSM, is Assistant Professor, Department of Physical Therapy, School of Health Professions, Northern Arizona University, CU Box 15105, Flagstaff, AZ 86011 (USA). Address all correspondence to Dr Arnall.

S Loy, PhD, FACSM, is Assistant Professor in Physical Education, California State University at Northridge, Northridge, CA 91330.

LJ Silvester, EdD, is Associate Professor in Physical Education, Brigham Young University, Provo, UT 84602 .

R Conlee, PhD, FACSM, is Associate Professor in Physical Educarion, Brigham Young University.

This study was funded by a Faculty Fellowship Award from Brigham Young University's College of Physical Education.

7his article was submitted April 3, 1989; was with the autbors for revision for 21 weeks; and was accepted January 22, 1990.

\author{
Arnold G Nelson \\ David A Arnall \\ Steven F Loy \\ L Jay Silvester \\ Robert K Conlee
}

content, citric acid enzymes, and oxidative capacity. ${ }^{12,4}$ There can also be increases in slow-twitch fiber area ${ }^{4}$ and possibly even a conversion of fibers from fast-twitch to slowtwitch. 5.6 Strength training, however, will reduce the mitochondrial density? and induce relatively small increases in oxidative enzymes. ${ }^{1,8}$ Increases in myokinase (adenylate kinase) activity 8,9 and fast-twitch fiber area ${ }^{1,3,8}$ have also been seen, but interconversion of fiber types has not been noted. ${ }^{3}$ These highly specific training effects have led to the widely accepted physiological principle known as the specificity of training. This theory is based on the idea that the muscles that are exercised will experience adaptive changes, whereas 


\begin{tabular}{|c|c|c|c|c|c|c|c|c|c|c|c|c|c|c|}
\hline \multirow[b]{3}{*}{ Group" } & \multirow{2}{*}{\multicolumn{2}{|c|}{ Age (yr) }} & \multicolumn{4}{|c|}{ Body Weight (kg) } & \multicolumn{4}{|c|}{ Body Fat $(\%)^{b}$} & \multicolumn{4}{|c|}{ Maximum Heart Rate (bpm) } \\
\hline & & & \multicolumn{2}{|c|}{ Pretest } & \multicolumn{2}{|c|}{ Posttest } & \multicolumn{2}{|c|}{ Pretest } & \multicolumn{2}{|c|}{ Posttest } & \multicolumn{2}{|c|}{ Pretest } & \multicolumn{2}{|c|}{ Posttest } \\
\hline & $\overline{\overline{\mathbf{x}}}$ & $\overline{\text { SEM }}$ & $\overline{\overline{\mathbf{x}}}$ & $\overline{\text { SEM }}$ & $\overline{\bar{x}}$ & $\overline{\text { SEM }}$ & $\overline{\overline{\mathbf{x}}}$ & SEM & $\overline{\overline{\mathbf{x}}}$ & $\overline{\text { SEM }}$ & $\overline{\overline{\mathbf{x}}}$ & $\overline{\text { SEM }}$ & $\overline{\bar{x}}$ & $\overline{\text { SEM }}$ \\
\hline $\operatorname{ITP}(n=5)$ & 27.0 & 1.1 & 69.5 & 3.8 & 70.4 & 4.1 & 7.9 & 1.1 & 8.1 & 1.5 & 192.0 & 6.2 & 190.0 & 2.4 \\
\hline $\operatorname{COMBO}(n=5)$ & 26.0 & 1.3 & 89.4 & 4.1 & 83.9 & 3.3 & 17.3 & 3.0 & 15.7 & 4.0 & 191.0 & 3.7 & 194.0 & 6.5 \\
\hline
\end{tabular}

${ }^{a} \mathrm{IPT}=$ increased torque production; $\mathrm{COMBO}=$ combination ITP-endurance; END $=$ endurance.

${ }^{b}$ Method of determining percentage of body fat was by hydrostatic weighing.

nonexercised muscles will experience little or no training effect. This training effect has been observed in muscles undergoing either a strength training program (ie, weight-lifting program) or an endurance exercise program (ie, jogging program).

Frequently, the concept of total fitness translates into a fitness program, which places heavy emphasis on both physical strength and cardiovascular endurance. However, many clinicians, trainers, and athletes believe that simultaneous training to increase torque production and cardiovascular endurance are counterproductive. This belief has no clear theoretical basis, but is supported by anecdotal evidence such as lost power with the initiation of endurance training or the inability to complete normal endurance training following weight lifting. If this idea is true, then the practice of maintaining cardiovascular endurance during a strength training program may be contraindicated. Unfortunately, very little research on this issue has been published. Hickson reported that endurance training inhibited force gains during 10 weeks of simultaneous training. ${ }^{10}$ Similarly, Dudley and Djamil found that concurrent training reduced torque gains at fast contraction velocities. ${ }^{11}$ Riedy and co-workers, however, reported no difference in the adaptive response to endurance training in rat muscle previously hypertrophied by surgical removal of the synergists. ${ }^{12}$ Even more germane to the present question was the finding of Gettman et al ${ }^{13}$ and Asfour et al ${ }^{14}$ that simultaneous training for force and endurance had no effect on the adaptive response to either mode.

In light of the limited amount of research available and the lack of agreement among published research, we decided to examine the matter further. Specifically, the purpose of this study was to evaluate the effect of a simultaneous training program for increased torque production and cardiovascular endurance on maximal oxygen consumption ( $\dot{\mathrm{V}}_{2}$ max ), quadriceps femoris muscle torque production, skeletal muscle fiber-type distribution and fiber area, and the activity of myokinase (adenylate kinase) and the mitochondrial marker enzyme citrate synthase. We hypothesized that the findings of this research would be due to the predominance at the cellular level of the endurance training adaptations (eg, increased oxidative capacity and fiber number, decreased fiber area) at the expense of normal torque training adaptations (eg, increased fiber area and reduction of oxidative capacity).

\section{Method}

\section{Subject Selection and Experimental Design}

The research methods and design met the guidelines established by an institutional review board governing the use of human subjects in research. All subjects were recruited using standard advertising methods. Eighteen healthy, active men who had not been engaged in any regular training program for at least one year volunteered to participate. Four subjects, however, did not complete the study. Descriptive data of the remaining 14 subjects are presented in Table 1. All subjects received complete information on the requirements and potential risks of the study, and written consent was obtained before any tests or training sessions were performed. The subjects were randomly divided into three groups: an increased torque production group (ITP Group, $n=5$ ), an endurance group (END Group, $\mathrm{n}=4$ ), and a combination increased torque production-endurance group (COMBO Group, $n=5$ ).

The ITP Group trained four days per week (Monday, Tuesday, Thursday, and Friday) on a Cybex ${ }^{\circledR}$ II isokinetic dynamometer ${ }^{*}$ with work outputs recorded from a Digital Work Integrator.* Training consisted of three sets of six maximal-effort repetitions of knee extension and flexion at $30 \% \mathrm{sec}$. Ninety seconds of rest were allowed between sets, and the right leg was always trained before the left leg. 
The END Group exercised on a Monarch ergometer ${ }^{\dagger}$ four days per week (Monday, Tuesday, Thursday, and Friday) at a constant pedaling rate of 83 rpm. During the first week, the subjects trained for 30 minutes at $75 \%$ of the maximum heart rate (MHR) achieved during the $\mathrm{V}_{2}$ max test. During week 2 , the intensity was increased to $80 \%$ of MHR. For weeks 3,4 , and 5 , the training duration was increased to 40,50 , and 60 minutes, respectively. At week 7 , the intensity was increased to $85 \%$ of MHR. For the remainder of the study, the subjects pedaled at $85 \%$ of MHR for $60 \mathrm{~min}$ utes per session.

The COMBO Group completed both the torque and endurance training regimens four days per week (Monday, Tuesday, Thursday, and Friday). Training for increased torque always preceded cycling, usually by $10 \mathrm{~min}$ utes. Daily bicycle work output averaged 250 and $232 \mathrm{~kJ}$ for the END and COMBO groups, respectively, at the beginning of the study and 232 and $729 \mathrm{~kJ}$ for the END and COMBO groups, respectively, at the end of the study.

The training program for each group lasted 20 weeks. Training sessions for each individual were monitored by a member of the research team.

\section{Testing}

Prior to, during, and after the training program, the subjects performed tests for torque production and cardiovascular power and submitted to biopsies of the vastus lateralis muscle. The tests were conducted over a period of three consecutive days. Day 1 was a period of rest with complete inactivity encouraged. On day 2 , the torque production test was performed, followed by the cardiovascular test. Muscle biopsies were obtained on day 3 . All tests were repeated at 11 - and 20 week periods at approximately the same time of day as the pretests.

Torque measurements used for analysis were the peak right knee extension torque $30^{\circ}, 60^{\circ}$, and $180^{\circ} / \mathrm{sec}$ using the Cybex ${ }^{\circledR}$ II isokinetic dynamometer in accordance with recommended procedures. ${ }^{15}$ Previous research has suggested that these measurements are reliable. ${ }^{16}$ Calibration of the isokinetic device was performed prior to the torque measurements following the manufacturer's guidelines. ${ }^{17}$ A practice trial was performed to familiarize each subject with the apparatus and was followed by three measured trials, with a 90 second recovery period between each trial to prevent fatigue. The subjects were instructed to exert approximately $75 \%$ maximal effort on the practice trial and to exert maximal extension and flexion force through the entire range of motion for the three measured trials. The best score from the three trials was used to represent the subject's torque.

Maximal oxygen consumption was assessed using a modified Bruce ${ }^{18}$ protocol on a Quinton Model 24-72 motor-driven treadmill. ${ }^{\ddagger}$ We chose to use the treadmill for the $\mathrm{VO}_{2}$ max testing for the following reasons. First, Hickson and co-workers ${ }^{10,19}$ have reported an increase in $\dot{\mathrm{V}}_{2}$ max on a bicycle ergometer and no change in $\dot{\mathrm{V}}_{2}$ max measured on a treadmill following 10 weeks of strength training. Most of the subjects in our study $(\mathrm{n}=10)$ had performed treadmill $\dot{\mathrm{VO}}_{2}$ max tests but not bicycle ergome-

${ }^{\dagger}$ Monarch-Crescent AB, PO Box 503, S-432 01, Varberg, Sweden.

${ }^{\ddagger}$ Quinton Instruments Inc, 2121 Terry Ave, Seattle, WA 98121-2791.

sBeckman Instruments Inc, Electronics Div, 3900 River Rd, Schiller Park, IL 60176.

"Technology Inc, Versatronics Div, 1825 Webster St, Dayton, OH 45404.

\#International Business Machine Corp, $1000 \mathrm{NW}$ 51st St, Boca Raton, Fl. 33432.

**Parke-Davis Instruments Inc, PO Box 2354, Chicago, IL 60675.

${ }^{\dagger+}$ Miles Inc, Diagnostics Div, 1025 Michigan St, Elkhart, IN 46515.

ter tests prior to volunteering for the study and were therefore accustomed to the protocol used. Finally, reliability calculations using a test-retest protocol showed the treadmill test to be more reliable than the bicycle ergometer test (treadmill $r=.97 \mathrm{vs}$ bicycle ergometer $r=.78$ ). The subjects in our study began the test walking at $45.6 \mathrm{~m} / \mathrm{min}$ at a $10 \%$ grade with subsequent increases in speed and grade made every two minutes until exhaustion occurred. Expired air was continuously monitored for percentage of oxygen by a Beckman OM-11 oxygen analyzer ${ }^{\S}$ and for percentage of carbon dioxide by a Beckman LB-2 carbon dioxide analyzer. ${ }^{\S}$ Inspired air volumes were measured by a Technology Model MTG pneumotachograph." All relevant information was constantly fed into an IBM Personal Computer, ${ }^{\#}$ and oxygen consumption $\left(\dot{\mathrm{V}}_{2}\right)$ values were computed at five-breath intervals. Heart rate was also continuously monitored on a Quinton Model 740 electrocardiographic data computer ${ }^{\ddagger}$ from a modified CM-5 electrode placement. Rhythm strips were recorded as needed on a Parke-Davis Model 2400 electrocardiographic unit."* Our criterion for $\dot{\mathrm{V}}_{2}$ max was an increase in $\dot{\mathrm{V}}_{2}$ of $\leq 2 \mathrm{~mL} \cdot \mathrm{kg}^{-1} \cdot \mathrm{min}^{-1}$ or a decrease in $\dot{\mathrm{V}}_{2}$ with succeeding increases in work load.

\section{Tissue Preparation and Analysis}

Muscle biopsies were taken from the right vastus lateralis muscle following the technique described by Bergstrom ${ }^{20}$ as modified by adding suction in the manner developed by Evans et al. ${ }^{21}$ Two muscle samples were taken from the same incision at each testing period, and all samples from all time periods were taken within $1 \mathrm{~cm}$ of each other. The first sample was embedded in Tissue-Tek II OCT compound ${ }^{\dagger \dagger}$ and frozen in 2-methylbutane cooled by liquid nitrogen and designated for histochemical analysis. The second sample was quickly frozen in liquid nitrogen and used for enzymatic analysis. All muscle samples were wrapped in aluminum foil and stored at $-80^{\circ} \mathrm{C}$ until 
Table 2. Torque Measurements (in Newton-meters per Kilogram of Body Weigbt) at Tbree Speeds

\begin{tabular}{|c|c|c|c|c|c|c|c|c|c|c|c|c|}
\hline \multirow[b]{2}{*}{ Group } & \multicolumn{2}{|c|}{ Pretest } & \multicolumn{2}{|c|}{ Posttest } & \multicolumn{2}{|c|}{ Pretest } & \multicolumn{2}{|c|}{ Posttest } & \multicolumn{2}{|c|}{ Pretest } & \multicolumn{2}{|c|}{ Posttest } \\
\hline & $\overline{\bar{x}}$ & $\overline{\text { SEM }}$ & $\overline{\overline{\mathbf{x}}}$ & $\overline{\text { SEM }}$ & $\overline{\bar{x}}$ & SEM & $\overline{\overline{\mathbf{x}}}$ & $\overline{\text { SEM }}$ & $\overline{\overline{\mathbf{x}}}$ & $\overline{\text { SEM }}$ & $\overline{\overline{\mathbf{x}}}$ & SEM \\
\hline ITP & 3.26 & 0.34 & 4.72 & $0.41^{b}$ & 2.99 & 0.35 & 4.01 & $0.29^{b}$ & 1.91 & 0.20 & 2.44 & $0.22^{b}$ \\
\hline СОMBO & 2.88 & 0.38 & 4.44 & $0.20^{b}$ & 2.76 & 0.37 & 3.92 & $0.19^{b}$ & 1.90 & 0.10 & 2.34 & $0.11^{D}$ \\
\hline
\end{tabular}

${ }^{a_{I T P}}=$ increased torque production; COMBO $=$ combination ITP-endurance; ENI $=$ endurance.

${ }^{b}$ Indicates significant difference from the pretest values $(p<.05)$.

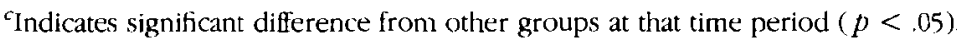

each subject's pretest, 11-week, and 20-week samples could be analyzed.

For the histochemical analysis, $10-\mu \mathrm{m}$ sections were cut in an ultra-lowtemperature microtome, adhered to microscope slide cover slips, and placed in columbia jars ${ }^{+7}$ for staining. The tissue samples were preincubated at $\mathrm{pH} 4.3,4.65$, and 10.3 and stained following the myofibrillar ATPase method. ${ }^{22,23}$ The mean muscle fiber area for each fiber type was determined using the $\mathrm{pH} 4.65$ slide by averaging the cross-sectional areas of 25 fibers, which had been traced from a microscopic projection and then measured by planimetry.

Activity levels of the enzymes citrate synthase and myokinase (adenylate kinase) were also measured in each muscle sample. Muscle citrate synthase activity was assayed on $5 \%$ homogenates following the procedure outlined by Srere. ${ }^{24}$ The technique outlined by Bergmeyer ${ }^{25}$ was used on $1 \%$ muscle homogenates to determine myokinase activity.

\section{Statistical Procedures}

Because of the loss of four subjects during the study, the composition of the groups appeared to be different. Therefore, an analysis of covariance, with the pretest score serving as the covariant, was performed. The scores of all parameters were analyzed using a three-way (treatment $x$ subjects $X$ time) split-plot, or mixed, design. For each main effect with a significant $F$ ratio, statistically significant differences between the means were established using Tukey's ${ }^{26}$ Honestly Significant Difference method. For all tests, the level of significance was set at .05 .

\section{Results}

\section{Torque}

The changes in torque for each group are presented in Table 2 . After 20 weeks, the ITP and COMBO groups had significant and comparable gains in torque. At $30 \% \mathrm{sec}$, the gains of the ITP Group ranged from $37 \%$ to $65 \%$ and COMBO Group gains ranged from $27 \%$ to $83 \%$. The END Group had a nonsignificant torque gain of $10 \%$. Torque gains at $60 \% \mathrm{sec}$ paral leled the gains at $30 \% \mathrm{sec}$. At $180 \% \mathrm{sec}$, however, the results were different. At this speed, all groups had a significant gain in torque with no difference in posttest scores between groups. Because we experienced mechanical problems with the dynamometer, which prevented accurate testing but did not hinder training, the 11-week torque test values were eliminated from the data analysis. Therefore, to obtain a representation of intermediate torque gains for each subject, both the daily work output and its squared value were multiply regressed against workout days. The average multiple regression curves for the ITP and COMBO groups are shown in the Figure. These multiple regression curves indicate a continued and progressive torque gain for both ITP and COMBO groups. The average linear (ITP Group $=.091$, COMBO Group $=.101$ ) and quadratic (ITP Group $=-5.9 \times$ $10^{-4}$, COMBO Group $=-5.7 \times$ $10^{-4}$ ) coefficients of these curves were compared, and no significant differences were found between the two curves.

\section{Maximal Oxygen Consumption}

The normalized $\dot{\mathrm{VO}}_{2}$ max values are presented in Table 3 . The final values for the COMBO and END groups were significantly greater than the corresponding initial values. After the first 11 weeks, the COMBO and END group gains were similar. Over the last half of the study, the END Group had a further significant increase in $\dot{\mathrm{VO}}_{2}$ max, whereas the COMBO Group showed no change. The $\dot{\mathrm{VO}}_{2}$ max of the ITP Group remained statistically unchanged during the study.

\section{Enzyme Activity}

Initially, there was no difference between groups in citrate synthase activity (in micromoles per gram per minute). The 11-week tests showed citrate synthase activity increased significantly in the END Group (97\%), but remained statistically unchanged

¥¥Thomas Scientific, PO Box 99, Swedesboro, NJ 08085-0099. 


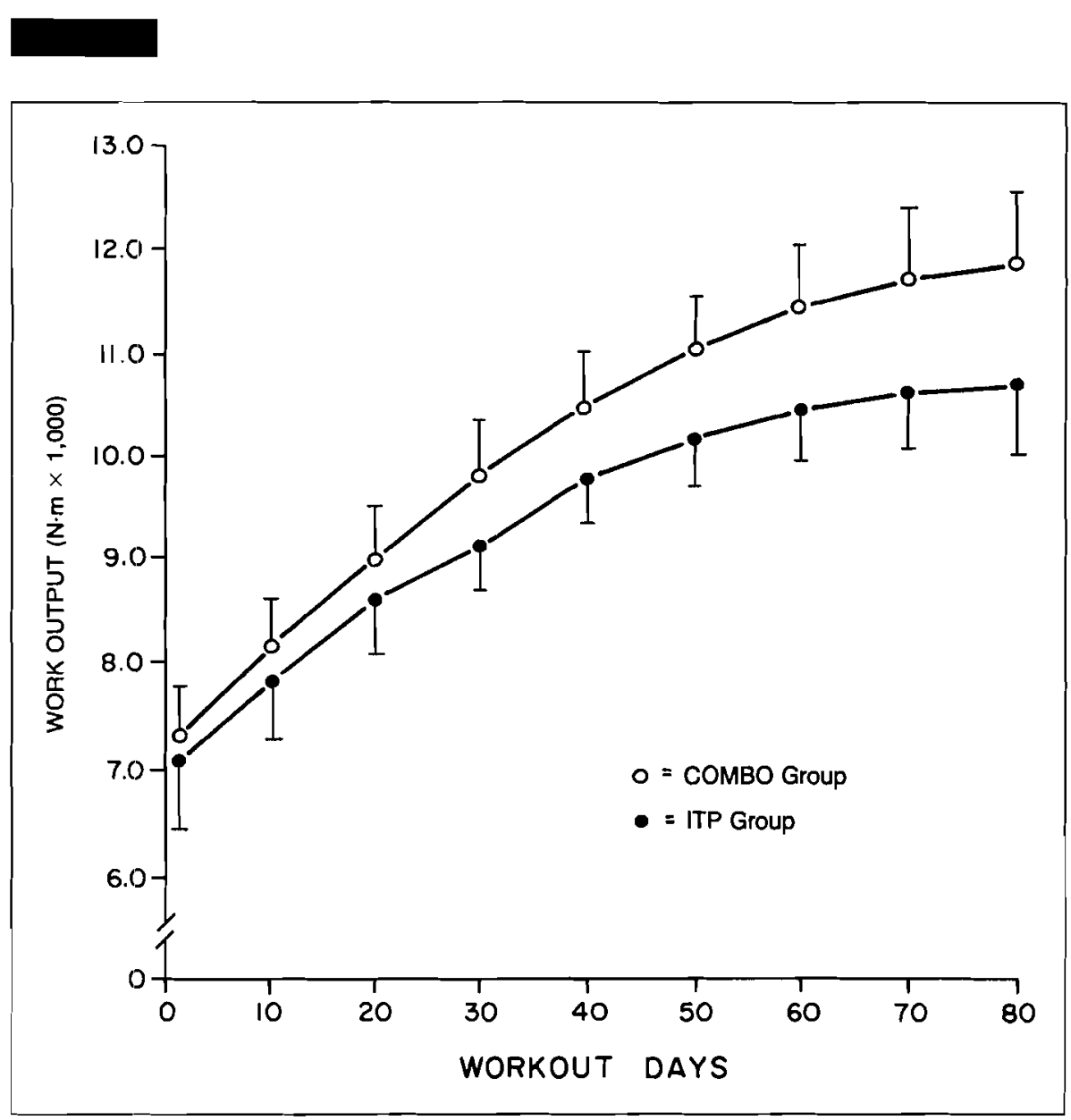

Figure. Average multiple regression curves for increased torque production (ITP) and combination ITP-endurance (COMBO) groups showing total work output per individual per workout period. Error bars represent the actual standard error of the mean for each group.

in the COMBO and ITP groups (Tab. 4). At 20 weeks, a slight but nonsignificant decline in activity had occurred in all groups compared with the 11week values.

There was also no initial difference among groups in myokinase activity (Tab. 4). During the course of the study, the ITP and END groups both showed apparent increases and the COMBO Group showed an apparent decrease in enzyme activity, but none of these changes were significant and the groups remained statistically similar.

\section{Muscle Fiber Morphology}

The results of the histological analysis are presented in Tables 5 and 6 . Because a single biopsy sample may not reflect the fiber type distribution of the whole muscle, ${ }^{27}$ caution should

\section{Discussion}

A limitation to these results revolves around the fact that four subjects withdrew from the study after the groups were initially randomized and training was initiated. These withdrawals reduced the size of each group and caused the ITP Group to be different with respect to initial body weight, body composition, and relative $\dot{\mathrm{VO}}_{2}$ max (Tabs. 1, 3). This outcome was unfortunate, but, because most of the important information in the results comes from contrasting the COMBO and END groups, we felt the dissimilarity between groups at the outset of the study was relatively inconsequential.

The findings of this study, along with those of Hickson ${ }^{10}$ and Dudley and Djamil, ${ }^{11}$ support the premise that simultaneous training programs for torque and endurance are counterproductive. These studies, however, disagree as to the nature of this incompatibility. Both of the previous studies ${ }^{10,11}$ found that endurance training interfered with torque development, but that torque training had no effect on aerobic adaptation. The present study, however, showed no difference in torque gains with simultaneous training but an inhibition in aerobic development, which occurred during the 11th through the 20th weeks of training. Numerous possible explanations exist for the apparent discrepancies between the previous studies and the present study.

First, upon closer evaluation, some of the differences are not very dramatic. For instance, in the Dudley and Djamil ${ }^{11}$ study, torque gains, as determined by isokinetic testing, were inhibited at only the faster speeds of movement but not at the slower movement speeds. Because we measured torque only at the relatively slow speeds and likewise found no inhibition in gain, our results are in agreement with those published by Dudley and Djamil. " Had we measured torque at faster speeds, we may have found a decrement in performance as well. 
Table 3. Maximal Oxygen Consumption (in Millititers per Kilogram of Body Weight per Minute)

\begin{tabular}{|c|c|c|c|c|c|c|}
\hline \multirow[b]{3}{*}{ Group" } & \multicolumn{6}{|c|}{ Week } \\
\hline & \multicolumn{2}{|l|}{0} & \multicolumn{2}{|l|}{11} & \multicolumn{2}{|l|}{20} \\
\hline & $\overline{\bar{x}}$ & $\overline{\text { SEM }}$ & $\overline{\overline{\mathbf{x}}}$ & $\overline{\text { SEM }}$ & $\overline{\bar{x}}$ & SEM \\
\hline ITP & 55.3 & 3.0 & 55.0 & $2.6^{\mathrm{b} . c}$ & 55.6 & 2.2 \\
\hline COMBO & 44.1 & 1.7 & 47.0 & $2.1^{d}$ & 48.8 & $2.0^{c-o}$ \\
\hline END & 45.5 & 4.9 & 50.0 & $5.7^{b, d}$ & 54.7 & $5.5^{d, f}$ \\
\hline
\end{tabular}

${ }^{a} \mathrm{ITP}=$ increased torque production; $\mathrm{COMBO}=$ combination ITP-endurance; END $=$ endurance.

${ }^{b}$ Indicates significant difference from COMBO Group within the time period $(p<.05)$.

${ }^{c}$ Indicates significant difference from END Group within the time period $(p<.05)$.

${ }^{d}$ Indicates significant difference from pretest values $(p<.05)$.

${ }^{e}$ Indicates significant difference from ITP Group within the time period $(p<.05)$.

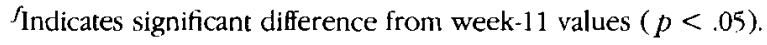

Table 4. Enzyme Activity (in Micromoles per Gram per Minute)

\begin{tabular}{|c|c|c|c|c|c|c|}
\hline \multirow[b]{3}{*}{ Group $^{a}$} & \multicolumn{6}{|l|}{ Week } \\
\hline & \multicolumn{2}{|l|}{$\overline{0}$} & \multicolumn{2}{|l|}{11} & \multicolumn{2}{|l|}{20} \\
\hline & $\overline{\mathbf{x}}$ & SEM & $\overline{\bar{x}}$ & SEM & $\overline{\bar{x}}$ & SEM \\
\hline \multicolumn{7}{|c|}{ Citrate synthase } \\
\hline ITP & 24.3 & 2.4 & 26.2 & 2.1 & 22.7 & 2.1 \\
\hline COMBO & 19.2 & 1.3 & 23.3 & 4.2 & 20.7 & 3.2 \\
\hline END & 17.4 & 2.1 & 34.2 & $7.2^{b, c}$ & 32.9 & $9.1^{b . c}$ \\
\hline \multicolumn{7}{|l|}{ Myokinase } \\
\hline ITP & 358.0 & 44.0 & 404.0 & 33.0 & 406.0 & 29.0 \\
\hline COMBO & 442.0 & 49.0 & 417.0 & 55.0 & 398.0 & 54.0 \\
\hline END & 390.0 & 27.0 & 430.0 & 53.0 & 489.0 & 60.0 \\
\hline
\end{tabular}

${ }^{a} \mathrm{ITP}=$ increased torque production; $\mathrm{COMBO}=$ combination ITP-endurance; END = endurance.

"Indicates significant difference from pretest values $(p<.05)$.

Indicates significant difference from other groups at that time period $(p<.05)$.

Second, our findings regarding aerobic adaptation are not different from those of Hickson ${ }^{10}$ or Dudley and Djamil ${ }^{11}$ if we only consider the results of the first 11 weeks of our study, which corresponds more closely to the length of time (7-10 weeks) of these earlier studies. As in those reports, we too noted no effects of torque training on aerobic adaptation. It was only after an additional 10 weeks of training that we noted such effects. It is possible that the differ- ences seen with the additional weeks of training could have been due to an overtraining response in the COMBO Group. We do not believe that overtraining was an important factor in this study. The subjects were continuously monitored for overtraining effects, and we never noticed any signs or received reports of overtraining symptoms in any of the subjects. So, the differences in the conclusions among the three studies regarding this aspect may be attributed to the different lengths of training time imposed by the designs. All of the differences in results among these studies can most likely be attributed to differences in methodology.

The diluted aerobic adaptation may be a function of the type of aerobic training program as well as the length of the program. Our study incorporated an endurance program of continuous cycling at $75 \%$ to $85 \%$ of MHR, whereas the previous two studies ${ }^{10.11}$ used an interval program requiring near-maximal effort during each work interval. Similar types of programs (intermittent vs continuous) have been shown by Henriksson and Reitman ${ }^{28}$ to recruit different muscle fiber types and therefore to elicit different aerobic adaptations. We speculate that high-intensity internal training for aerobic endurance combined with weight training for strength, as used by Hickson ${ }^{10}$ and Dudley and Djamil, ${ }^{11}$ recruit the type II fibers and perhaps create a combined stress that cannot be adjusted to adequately over time; thus, one adaptation (endurance) predominates over the other (increased torque production). The mechanism for this recruitment is not clear. In this study, the stimulus from combined training seemed to be distributed uniformly over the different fibers and resulted in no interference of torque production adaptations. This finding is supported by our observation that type I and type II fibers hypertrophied in both COMBO and END groups, but only type II fibers hypertrophied in the ITP Group. This uniform effect across fibers, however, seemed to interfere with normal aerobic adaptation, as demonstrated by the lack of increase in citrate synthase activity and a reduced rise in $\mathrm{VO}_{2}$ max in the COMBO Group. Why this interference occurred is not entirely clear. MacDougall and associates, ${ }^{7}$ however, found that strength training tended to dilute mitochondrial volume in type Ila fibers because of hypertrophy. Such a dilution could lead to a reduction in relative aerobic capacity. Although both COMBO and END groups in our study produced hypertrophy in type IIa fibers, it would appear that the greater, but nonsignifi- 
Table 5. Fiber Type Distribution (in Percentages)

\begin{tabular}{|c|c|c|c|c|c|c|c|c|c|c|c|c|c|c|c|c|c|c|}
\hline \multirow[b]{3}{*}{ Group } & \multicolumn{6}{|c|}{ Type I } & \multicolumn{6}{|c|}{ Type lla } & \multicolumn{6}{|c|}{ Type Ilb } \\
\hline & \multicolumn{2}{|c|}{ Wk 0} & \multicolumn{2}{|c|}{ Wk 11} & \multicolumn{2}{|c|}{ Wk 20} & \multicolumn{2}{|c|}{ Wk O } & \multicolumn{2}{|c|}{ Wk 11} & \multicolumn{2}{|c|}{ Wk 20} & \multicolumn{2}{|c|}{$\overline{\text { Wk } 0}$} & \multicolumn{2}{|c|}{ Wk 11} & \multicolumn{2}{|c|}{ Wk 20} \\
\hline & $\overline{\bar{x}}$ & $\overline{\text { SEM }}$ & $\overline{\overline{\mathbf{x}}}$ & $\overline{\text { SEM }}$ & $\overline{\bar{x}}$ & $\overline{\text { SEM }}$ & $\overline{\bar{x}}$ & $\overline{\text { SEM }}$ & $\overline{\bar{x}}$ & $\overline{\text { SEM }}$ & $\overline{\bar{x}}$ & $\overline{\text { SEM }}$ & $\overline{\overline{\mathbf{x}}}$ & $\overline{\text { SEM }}$ & $\overline{\overline{\mathbf{X}}}$ & $\overline{\text { SEM }}$ & $\overline{\overline{\mathbf{X}}}$ & $\overline{\text { SEM }}$ \\
\hline ITP & 44 & 2 & 43 & 4 & 49 & 3 & 42 & 2 & 43 & 2 & 40 & 2 & 13 & 2 & 14 & 4 & 11 & 5 \\
\hline СОМВО & 31 & 6 & 39 & 6 & $40^{\circ}$ & 4 & 49 & 6 & 41 & 2 & $40^{b}$ & 3 & 21 & 4 & 20 & 4 & 20 & 3 \\
\hline
\end{tabular}

${ }^{a} \mathrm{ITP}=$ increased torque production; $\mathrm{COMBO}=$ combination ITP-endurance; END $=$ endurance.

${ }^{b}$ Indicates significant difference from pretest values $(p<.05)$.

cant, hypertrophy in the COMBO

Group compared with that of the END Group ( $25 \%$ vs $11 \%$, respectively) lends some support for the dilution premise.

\section{Clinical Applications}

When optimal torque gains and maintenance of cardiovascular endurance are desired, exercise training programs should be similar to that used in this study, that is, a program to increase torque production coupled with an endurance program of moderate intensity and long duration. For those individuals who want to increase cardiovascular endurance rather than rapidly increase torque production, however, the exercise training program should be similar to that used by Hickson and colleagues ${ }^{10,19}$ and Dudley and
Djamil, ${ }^{11}$ that is, a torque program coupled with an endurance program consisting of high-intensity intervals. These recommendations should only be followed when the torque and endurance programs involve the same muscle groups. Obviously, further work is necessary to determine the best simultaneous training program that results in optimal adaptation to both stimuli.

These recommendations are based on the results of studies performed on healthy, active individuals and are ideally suited to the clientele commonly found in a fitness-wellness setting or in an athletic program. Clinicians should be careful about applying these recommendations to patient populations. It is not known at this time whether the counterproductivity between these training methods would manifest itself in a population with severely compromised torque production and endurance.

\section{Conclusions}

The results of this study indicate that simultaneous training for torque pro duction and endurance may inhibit the normal adaptation to either treatment when performed alone. Based on our results, the normal adaptations to endurance training appear to be inhibited by simultaneous torque training following the initial 11 weeks of a simultaneous training program. This interference is evidenced by a lack of increase in $\dot{\mathrm{VO}}_{2}$ max and oxida tive enzymes. We hypothesize that this interference probably depends on the nature and intensity of the individual training program. We believe the controlling factor may lie more with the

Table 6. Muscle Fiber Area (in Square Micrometers)

\begin{tabular}{|c|c|c|c|c|c|c|c|c|c|c|c|c|c|c|c|c|c|c|}
\hline \multirow[b]{3}{*}{ Group } & \multicolumn{6}{|l|}{ Type I } & \multicolumn{6}{|c|}{ Type Ila } & \multicolumn{6}{|c|}{ Type Ilb } \\
\hline & \multicolumn{2}{|l|}{ Wk 0} & \multicolumn{2}{|l|}{ Wk 11} & \multicolumn{2}{|l|}{ Wk 20} & \multicolumn{2}{|l|}{$\overline{\text { Wk } 0}$} & \multicolumn{2}{|c|}{ Wk 11} & \multicolumn{2}{|l|}{ Wk 20} & \multicolumn{2}{|l|}{$\overline{W k 0}$} & \multicolumn{2}{|c|}{ Wk 11} & \multicolumn{2}{|l|}{ Wk 20} \\
\hline & $\overline{\bar{x}}$ & $\overline{\text { SEM }}$ & $\overline{\overline{\mathbf{x}}}$ & $\overline{\text { SEM }}$ & $\overline{\overline{\mathbf{x}}}$ & $\overline{\text { SEM }}$ & $\overline{\bar{x}}$ & $\overline{\text { SEM }}$ & $\overline{\overline{\mathbf{x}}}$ & $\overline{\text { SEM }}$ & $\overline{\bar{X}}$ & $\overline{\text { SEM }}$ & $\overline{\bar{x}}$ & $\overline{\text { SEM }}$ & $\overline{\overline{\mathbf{X}}}$ & $\overline{\text { SEM }}$ & $\overline{\bar{x}}$ & $\overline{\text { SEM }}$ \\
\hline ITP & 4,813 & 350 & 4,894 & 356 & 4,736 & 316 & 6,502 & 670 & 6,698 & 545 & 7,355 & 796 & 4,838 & 327 & 5,376 & 439 & $5,571^{b}$ & 399 \\
\hline COMBO & 4,638 & 578 & 5,149 & 302 & $5,330^{b . c}$ & 419 & 6,920 & 289 & 7,596 & 538 & $8,629^{b, d}$ & 412 & 6,006 & 336 & 6,237 & 319 & $6,900^{b, d}$ & 513 \\
\hline END & 4,698 & 590 & 4,732 & 569 & $5,642^{b-d}$ & 655 & 6,705 & 776 & 6,528 & 756 & $7,472^{b, d}$ & 767 & 5,621 & 643 & 5,676 & 650 & $6,067^{b}$ & 707 \\
\hline
\end{tabular}

${ }^{a} \mathrm{ITP}=$ increased torque production; $\mathrm{COMBO}=$ combination ITP-endurance; END $=$ endurance.

${ }^{b}$ Indicates significant difference from pretest values $(p<.05)$.

'Indicates significant difference from ITP Group values $(p<.05)$.

${ }^{d}$ Indicates significant difference from 11 -week values $(p<.05)$. 
endurance training stimulus (moderate intensity-long duration vs high intensity-interval exercise). Therefore, the results indicate that care should be maintained when prescribing exercise training programs.

\section{References}

1 Edgerton VR: Mammalian muscle fiber types and their adaptability. American Zoology 18:113-125, 1978

2 Holloszy JO, Coyle EF: Adaptations of skeletal muscle to endurance exercise and their metabolic consequences. J Appl Physiol $56: 831-838,1984$

3 McDonagh MJN, Davies CTM: Adaptive response of mammalian skeletal muscle to exercise with high loads. Eur J Appl Physiol 52:139-155, 1984

4 Gollnick PD, Armstrong RB, Saltin B, et al: Effect of training of enzyme activity and fiber composition of human skeletal muscle. J Appl Physiol 34:107-111, 1973

5 Green HJ, Klug GA, Reichmann H, et al: Exercise-induced fibre type transitions with regard to myosin, parvalbumin, and sarcoplasmic reticulum in muscles of the rat. Pflugers Arch 400:432-438, 1984

6 Simoneau JA, Lortie G, Boulay MR: Human skeletal muscle fiber type alteration with high intensity intermittent training. Eur J Appl Physiol 54:250-253, 1985

7 MacDougall JD, Sale DG, Moroz JR: Mitochondrial volume density in human skeletal muscle following heavy resistance training. Med Sci Sports 11:164-166, 1979

8 Costill DL, Coyle EF, Fink WF, et al: Adaptations in skeletal muscle following strength training. J Appl Physiol 46:96-99, 1979

9 Thorstensson A, Hulten B, vonDobeln W, et al: Effect of strength training on enzyme activity and fiber characteristics in human skeletal muscle. Acta Physiol Scand 96:392-398, 1976

10 Hickson RC: Interference of strength development by simultaneous training for strength and endurance. Eur J Appl Physiol 45:255-263, 1980

11 Dudley GA, Djamil R: Incompatibility of endurance and strength training modes of exercise. J Appl Physiol 59:1446-1451, 1985

12 Riedy M, Moore RL, Gollnick PD: Adaptive response of hypertrophied skeletal muscle to endurance training. J Appl Physiol 59:127-131, 1985

13 Gettman LR, Ward P, Hagan RD: A comparison of combined running and weight training with circuit weight training. Med Sci Sports Exerc 14:229-234, 1982

14 Asfour SS, Ayoub MM, Mital A: Effects of an endurance and strength training programme on lifting capacity of males. Ergonomics 27:435-442, 1984

15 Isolated Joint Testing and Exercise: A Handbook for Using Cybex ${ }^{\mathbb{}}$ II and the UBXT Ronkonkoma, NY, Cybex, Div of Lumex Inc, 1983, pp 13-19, 69-70

16 Nelson AG, Chambers RS, McGown CM, et al: Proprioceptive neuromuscular facilitation versus weight training for enhancement of muscular strength and athletic performance. Journal of Orthopaedic and Sports Physical Therapy 7:250-253, 1986
17 Cybex ${ }^{\circledast}$ II Calibration Procedures and Record Card. Ronkonkoma, NY, Cybex, Div of Lumex Jnc, 1980, pp 1-4

18 Bruce RA, McDonough JR: Stress testing in screening for cardiovascular disease. Bull NY Acad Med 45:1288-1305, 1969

19 Hickson RC, Rosenkoetter MA, Brown MM: Strength training effects on aerobic power and short-term endurance. Med Sci Sports Exerc $12: 336-339,1980$

20 Bergstrom J: Muscle electrolytes in man Scand J Clin Lab Invest [Suppl] 68:1-110, 1962 21 Evans WJ, Phinney SD, Young VR: Suction applied to a muscle biopsy maximizes sample size. Med Sci Sports Exerc 14:101-102, 1982

22 Brooke MH, Kaiser KK: The use and abuse of muscle histochemistry. Ann NY Acad Sci 228:121-144, 1974

23 Padykula HA, Herman E: The specificity of the histochemical method for adenosine triphosphatase. J Histochem Cytochem 3:170195, 1955

24 Srere PA: Citrate synthase. Methods Enzymol 13:3-6, 1969

25 Bergmeyer J: Determination of myokinase activity. In Bergmeyer J (ed): Methods of Enzy. matic Analysis. London, England, Academic Press Inc, 1974, pp 486-487

26 Tukey JW: Exploratory Data Analysis. Reading, MA, Addison-Wesley Publishing Co Inc, 1977

27 Lexell J, Henriksson-Larsen $K$, winbald B: Distribution of different fiber types in human skeletal muscles: Effects of aging studied in whole muscle cross sections. Muscle Nerve 6:588-595, 1983

28 Henriksson J, Reitman JS: Quantitative measures of enzyme activities in type I and type II muscle fibers of man after training. Acta Physiol Scand 97:392-397, 1976 